\title{
Revamping the Image of Science for the Anthropocene
}

\author{
S. Andrew Inkpen* and C. Tyler DesRoches ${ }^{\dagger}$
}

Science is often described as a set of discipline-specific paradigms that share common concepts, theories, and practices. However, during the Anthropocene, this image of science has become inapplicable and is potentially damaging. Today, many natural and social scientists confront problems and systems that transgress traditional disciplinary boundarieswe focus on ecologists and economists. We claim that these changes justify rethinking the prevailing image of science, along with the relation between life scientists and social scientists. The time is ripe to recognize the new normal in Anthropocene science and spell out what transdisciplinary problems entail for research practice. We suggest three central issues should be recognized by any adequate characterization of the new normal. First, given the preponderance of natural-social systems in the Anthropocene, we claim that there are circumstances when analyzing such systems requires new methodological standards. Second, Anthropocene science will increasingly involve discussions that link the normative and the scientific, where questions of how and what we should study imply questions of value. Finally, because the vast majority of Anthropocene science will be interdisciplinary, we identify some of the mechanisms that allow researchers to engage with social scientists and scholars in the humanities.

\section{Keywords}

Anthropocene $\bullet$ interdisciplinarity $\bullet$ ecology $\bullet$ economics $\bullet$ Kuhn, Thomas $\bullet$ natural-social systems

In 2016, a multidisciplinary body of scholars within the International Commission on Stratigraphy - the Anthropocene Working Group-recommended that the world officially recognize the Anthropocene as a new geological epoch (Voosen 2016; Zalasiewicz et al. 2017). The most contested claim about the Anthropocene, that humans are a major geological and environmental force on par with natural forces, has proven to be a hotbed for discussion well beyond the science of geology (Steffen et al. 2007; Chakrabarty 2009; Thomas 2014; Bonneuil and Fressoz 2015; Corlett 2015; Purdy 2015). One reason for this is that it compels many natural and social

* Department of Philosophy, Brandon University, Brandon, MB R7A 6A9, Canada, inkpena@brandonu.ca

$\dagger$ School of Sustainability, School of Historical, Philosophical \& Religious Studies, Arizona State University, Tempe, AZ 85281, USA

Received 19 September 2018; Revised 25 November 2018; Accepted 26 November 2018 doi:10.3998/ptpbio.16039257.0011.003

○ OPEN ACCESS - PTPBIO.ORG 
scientists to confront problems and systems that transgress traditional disciplinary boundaries, and as a result, calls for interdisciplinary research are now gaining traction (Castree 2014; Ledford 2015; Rylance 2015; Bostic 2016; Ellis et al. 2016; Bostic and Howey 2017). Proponents of such transgressions have dubbed the new scientific order that will result "Anthropocene Science" (Ellis and Trachtenberg 2013), and rhetoric notwithstanding, such discussions exemplify how recent changes within science justify rethinking a prevailing image of how science is done, and with it, the working relationship between scholars in the humanities, natural scientists, and social scientists.

Science is usually described in disciplinary terms. Scientific disciplines, as social-epistemic unities, share common concepts, theories, and practices, often called paradigms (Andersen 2016). The idea of a scientific paradigm is most closely associated with the historian of science Thomas Kuhn. On his account, "normal" or everyday science solves discipline-defined problems with discipline-defined tools, and collaboration occurs mainly within boundaries between scientists who are "disciplined" into speaking the same language. Normal science is interspersed with periods of revolutionary science, when troubling anomalies build to a crisis point and a new paradigm emerges.

The Kuhnian image of science, so compelling among scientists and the public, may have captured mid-twentieth-century problems and practices, but it fails to capture the way current science is and should be done. An image of scientific practice as a set of discipline-specific paradigms is inapplicable and potentially damaging (Functowitz and Ravetz 1993). Science, as it is practiced today, is increasingly transdisciplinary in its problems and methods. The pervasiveness of the human footprint implied by the Anthropocene means that science today also requires mechanisms that allow natural scientists to engage more frequently with their colleagues in the social sciences and scholars in the humanities. It is time to recognize the novelty of Anthropocene science and spell out what transdisciplinary problems entail for research practice. Of course, challenges to disciplinarity themselves are not new, and so calls for interdisciplinarity that have origins in the Anthropocene are perhaps best viewed as the result of a building frustration with the siloed nature of the academy. Regardless, the Anthropocene has become a uniquely powerful destabilizing force, and thus offers novel opportunities for rethinking science's image. Focusing on relations between ecologists and economists, we want to open the discussion with three central issues that should be considered in any adequate characterization of this new "normal science" (to use Kuhn's phrase).

\section{Does a New Ontology Require New Methodological Standards?}

Ecologist Robert O'Neill and economist James Kahn have claimed that the "ecological paradigm isolates human activity in a box labeled 'disturbances' [while the] economic paradigm, in turn, isolates ecosystem dynamics in a box labeled 'externalities'” (O’Neill and Kahn 2000, 333). In fact, throughout most of the twentieth century, interactions between ecologists and economists were hampered by ideas of disciplinary purity: "pure" ecologists study "natural"i.e., non-human systems - and "pure" economists study a specific set of human causes (Martin et al. 2012; Inkpen 2017a; Inkpen 2017b; DesRoches et al. forthcoming). Underwriting this was a view of a tidy world, neatly divided into either natural or social systems. One of the central claims of the Anthropocene is that the distinction between human and natural systems is no longer firm. Not only does the Anthropocene proclaim an abrupt and irreversible departure from the Holocene, it posits an intermingling of the human and the non-human in systems at every scale (Ellis et al. 2013; Waters et al. 2016). 
Yet, current debates over Anthropocene science leave unanalyzed the relation between the ubiquity of human-natural systems and current methodological standards-between what the world is like and how it should be studied. Are natural-social systems better considered as wholes or as objects to be broken down and studied by natural and social sciences operating independently? How should we deal with the fact that different sciences bring different disciplinaryspecific forms of quality assessment to the table? How do we amalgamate and evaluate evidence from different sources?

Some studies show that it would be unwise to ignore coupling between social and natural systems. For example, the treatment of humans as "disturbances" in ecology has given rise to models that are inapplicable when such disturbances are present (Inkpen 2017). Helmus et al. (2014) have shown that island biogeography theory, long used to inform environmental policy decisions, fails to explain the distribution of Anolis lizards on Caribbean islands because the theory lacks anthropogenic variables, such as the human transport of lizards on shipping vessels which is a function of economic variables such as trade agreements and embargos. Anole species richness, it turns out, is a negative function of economic isolation. Among economists, Settle et al. (2002) have shown that modelling the inland fishery of Yellowstone Lake without accounting for feedback links between the economic system and ecological system end up with inferior predictions and policy prescriptions. Failing to model such links places the Yellowstone cutthroat trout (Oncorbynchus clarki bouvieri) at a greater risk. These cases suggest that the new ontology of mixed natural-social or hybrid phenomena requires a shift in methodological standards. Rather than using methods to isolate what are perceived to be separate and distinct systems, hybrid systems are better considered as wholes. As in the case of Helmus et al., this may be as simple as the substitution of a variable strongly influenced by economic trends ("economic isolation") for one that is common in traditional discipline-specific, ecological models ("geographical isolation"). But there is no guarantee and the methods required to understand hybrid systems may be much more disruptive to traditional approaches.

\section{The Normative and the Scientific}

Science in the Anthropocene will increasingly involve discussions that inextricably link the normative and the scientific, where questions of how and what we should study imply questions of value. For decades, it has been commonplace for philosophers of science to distinguish two kinds of values in science: cognitive and non-cognitive. Cognitive (or epistemic) values-such as accuracy, consistency, scope, fruitfulness, generality, and simplicity-are indispensable to the scientific enterprise because they underwrite the norms of scientific practice and method, and are often truth-conducive (that is, they help us gain true knowledge of the world). The extent to which science is (or should be) free of non-cognitive values-such as personal preferences, political persuasion, and financial interests-is more hotly disputed, but the latest evidence suggests that such values do influence various aspects of scientific activity, such as what questions to engage, which methods to employ, and how to interpret results (Douglas 2013).

There have been virulent debates about the values embedded in the very idea of "the Anthropocene," primarily because many take the Anthropocene to affirm the belief that the human place in nature ought to be managerial. Debates about the values and politics entailed by Anthropocene science have been rancorous, for example, this has been so for discussions about the science of "novel ecosystems."

Novel ecosystems are assemblages of species not previously occurring and often created through human-induced environmental changes (Hobbs et al. 2013; Hobbs et al. 2014). Scien- 
tists increasingly recognize that much of the planet consists of such ecosystems, but they disagree about its normative dimensions (Marris 2009; Martin et al. 2012). Marris summarizes,

In the end, the question of novel ecosystems, like so many questions in ecology and conservation, boils down to what should be valued most in nature. For people who value processes [...] novel ecosystems are great hubs of active evolution. For those who value ecosystem services, any novel ecosystem could be better or worse than what came before depending on how it operates. For those who care about global extinctions or about preserving historical ecosystems, they are bad news. (2009, 453)

In any case, "novel ecosystem" is not simply a descriptive phrase but one that carries normative weight. Corlett $(2015,39)$ has cautioned that "if humans are now the dominant ecological force on the planet, then it is impossible to separate 'humans' and 'nature' in the way that conservation has traditionally tried to do." How, then, do we proceed? The debate over novel ecosystems has been a debate about conceptual and empirical problems in defining the concept and simultaneously a debate about the normative or value-laden assumptions that seem inseparable from promoting it (Murcia et al 2014). We do not take sides in these debates here. Instead, we see them as demanding a different account of science and values in which "thick" concepts, those containing both descriptive and normative elements, must be fully acknowledged as part of the new status quo. Anthropocene science is not and cannot be divorced from social values. Moving forward, natural scientists need to more fully embrace their colleagues in the social sciences and humanities who are specifically trained to deal with such issues.

\section{Encouraging Productive Transgression}

It is one thing to argue that science in the Anthropocene must be interdisciplinary, and quite another to identify and promote the mechanisms required for its success. Interdisciplinary work faces many obstacles: the norms governing its success are less codified than intradisciplinary work; tensions arising from the distinct goals of researchers from different disciplines hinders collaboration; ingrained cultural hierarchies privilege some sciences over others; and institutional features of funding structures make "research that transcends conventional academic boundaries [...] harder to fund, do, review and publish — and those who attempt it struggle for recognition and advancement" (Nature 2015, 305). But if transdisciplinary problems require interdisciplinary treatments, we must find a way around such obstacles.

There is no definitive recipe for successful interdisciplinary science in every context. However, one promising way forward is to promote the kind of science envisioned by the National Science Foundation's new Growing Convergence Research program, which requires participating scientists and scholars to engage in problem-driven research that is characterized by deep integration across disciplines. Insightful principles for successful interdisciplinary science have also been outlined by those who have achieved some success (Brown et al. 2015). Forging broad, shared missions that articulate the overall goal of the collaboration are important. Training of researchers must give rise to those that are so-called "T-shaped," that is, able to cultivate their own discipline while being willing to engage with other disciplines despite different norms and theories. In order for dialogue to be constructive, researchers must be committed to avoiding disciplinary jargon, empathic and respectful of other disciplinary norms, and constantly in communication about what has actually resulted in successful collaborations. At the institutional level, there must be clearly-defined performance indicators and rewarding academic pathways for T-shaped researchers. 
To this list, we add the need for scientists to cultivate the wisdom to distinguish between productive and unproductive interdisciplinary collaboration. In this regard, one potentially helpful way forward is to take lessons from recent philosophy of science that has specifically addressed the reasons behind successful interdisciplinary work (see special issues: Brigandt 2013; GrüneYanoff and Mäki 2014; De Grandis and Efstathiou 2016). Collaborative gains are not always self-evident, and the ability to perceive them is itself an epistemic virtue that should be fostered explicitly (Macleod and Nagatsu 2016). Moreover, scholars should not underestimate the significance of articulating a new and shared image for how science in the Anthropocene should operate. Old images of science do not retire gracefully, but a fresh image that better captures transdisciplinary research problems and methods is required to facilitate the kind of productive transgressions that the Anthropocene demands. This highlights the role of science studies scholars in the humanities, who possess the expertise to work productively at the intersection between science and the public sphere-where images of science get reproduced and acted upon-and who, in conjunction with scientists, can articulate an image that avoids the pitfalls of the past. There are many possibilities here, and although we do not pretend to offer a comprehensive replacement image, it should be noted that there are more and less disruptive options: from an image of science with revamped existing disciplines that seamlessly incorporate tools from humanistic disciplines, through the further development of new and existing interdisciplines, such as ecological economics, that have their own disciplinary structures-including journals - to the complete revamping of science tout court, where disciplinary boundaries are less normative and more porous across the board. 1 Of course, there is no guarantee that these mechanisms alone will translate into successful interdisciplinary science. However, they do provide us with points of departure for restructuring scientific interactions during the Anthropocene.

\section{Literature cited}

Andersen, H. 2016. "Collaboration, Interdisciplinarity, and the Epistemology of Contemporary Science." Studies in the History and Philosophy of Science 56: 1-10.

Bonneuil, C., and J. Fressoz. 2015. The Shock of the Anthropocene: The Earth, History and Us. New York: Verso.

Bostic, H. 2016. "The Humanities Must Engage Global Grand Challenges.” Chronicle of Higher Education, March 30, 2016.

Bostic, H., and M. Howey. 2017. “The Anthropocene Needs the Liberal Arts.” Anthropocene 18: 105110.

Brigandt, I. 2013. "Integration in Biology: Philosophical Perspectives on the Dynamics of Interdisciplinarity." Studies in History and Philosophy of Biological and Biomedical Sciences 44: 461-465.

Brown, R., A. Deletic, and T. Wong. 2015. "How to Catalyse Collaboration." Nature 525: 315-317.

Castree, N. 2014. "The Anthropocene and the Environmental Humanities: Extending the Conversation." Environmental Humanities 5: 233-260.

Chakrabarty, D. 2009. “The Climate of History: Four Theses.” Critical inquiry 35: 197-222.

Corlett, R. 2015. “The Anthropocene Concept in Ecology and Conservation.” Trends in Ecology \& Evolution 30: 36-41.

De Grandis, G., and S. Efstathiou. 2016. "Introduction—Grand Challenges and Small Steps.” Studies in History and Philosophy of Biological and Biomedical Sciences 56: 39-47.

\footnotetext{
${ }^{1}$ We thank a reviewer for raising this point and for these suggestions.
} 
DesRoches, C. T., S. A. Inkpen, and T. L. Green. Forthcoming. "The Eroding Artificial/Natural Distinction? Some Consequences for Ecology and Economics." In Philosophy and Interdisciplinary Social Science: A Dialogue, edited by M. Nagatsu and A. Ruzzene. London, UK: Bloomsbury Publishing.

Douglas, H. 2009. Science, Policy, and the Value-Free Ideal. Pittsburgh: University of Pittsburgh Press.

Ellis, E., J. Kaplan, D. Fuller, S. Vavrus, K. Goldewijk, and P. Verburg. 2013. "Used Planet: A Global History." Proceedings of the National Academy of Sciences 110: 7978-7985.

Ellis, E., M. Maslin, N. Boivin, and A. Bauer. 2016. "Involve Social Scientists in Defining the Anthropocene." Nature Nerws 540: 192.

Ellis, M., and Z. Trachtenberg. 2013. "Which Anthropocene Is It to Be? Beyond Geology to a Moral and Public Discourse." Earth's Future 2: 122-125.

Funtowicz, S. O., and J. R. Ravetz. 1993. "Science for the Post-Normal Age." Futures 25: 739-755.

Grüne-Yanoff, T., and U. Mäki. 2014. "Introduction: Interdisciplinary model exchanges." Studies in History and Philosophy of Science 48: 52-59.

Helmus, M., D. L. Mahler, and J. Losos. 2014. "Island Biogeography of the Anthropocene.” Nature 513: 543-546.

Hobbs, R. J., E. Higgs, and C. Hall. 2013. Novel Ecosystems: Intervening in the New Ecological World Order. New Jersey: John Wiley \& Sons.

Hobbs, R. J., E. Higgs, C. M. Hall, P. Bridgewater, F. S. Chapin, E. C. Ellis, J. J. Ewel, et al. 2014. "Managing the Whole Landscape: Historical, Hybrid, and Novel Ecosystems." Frontiers in Ecology and the Environment 12: 557-564.

Inkpen, S. A. 2017a "Demarcating Nature, Defining Ecology: Creating a Rationale for the Study of Nature's 'Primitive Conditions'” Perspectives on Science 25: 355-92.

Inkpen, S. A. 2017b. “Are Humans Disturbing Conditions in Ecology?” Biology E Philosophy 32: 5171.

Ledford, H. 2015. “Team Science.” Nature 525: 308-311.

MacLeod, M., and M. Nagatsu. 2016. "Model Coupling in Resource Economics: Conditions for Effective Interdisciplinary Collaboration.” Philosophy of Science 83: 412-433.

Marris, E. 2009. "Ragamuffin Earth.” Nature 460: 450-453.

Martin, L., B. Blossey, and E. Ellis. 2012. "Mapping Where Ecologists Work: Biases in the Global Distribution of Terrestrial Ecological Observations." Frontiers in Ecology and the Environment 10: 195-201.

Murcia, C., J. Aronson, G. H. Kattan, D. Moreno-Mateos, K. Dixon, and D. Simberloff. 2014. "A Critique of the 'Novel Ecosystem' Concept.” Trends in Ecology E Evolution 29: 548-53.

Nature. 2015. "Why Interdisciplinary Research Matters." 525 (305), September 17, 2015. doi:10.1038/525305a

O’Neill, R., and J. Kahn. 2000. "Homo economus as a Keystone Species." BioScience 50: 333-337.

Purdy, J. 2015. After Nature: A Politics for the Anthropocene. Cambridge: Harvard University Press.

Rylance, R. 2015. “Global Funders to Focus on Interdisciplinarity." Nature 525: 313-315.

Settle, C., T. Crocker, and J. Shogren. 2002. "On the Joint Determination of Biological and Economic Systems.” Ecological Economics 42: 301-311.

Steffen, W., P. Crutzen, and J. R. McNeill. 2007. "The Anthropocene: Are Humans Now Overwhelming the Great Forces of Nature?" Ambio 36: 614-621. 
Thomas, J. A. 2014. "History and Biology in the Anthropocene: Problems of Scale, Problems of Value." American Historical Review 119: 1587-1607.

Voosen, P. 2016. “Anthropocene Pinned to Postwar Period.” Science 353: 852-853.

Waters, C. N., J. Zalasiewicz, C. Summerhayes, A. D. Barnosky, C. Poirier, A. Gałuszka, A., A. Cearreta, et al. 2016. "The Anthropocene Is Functionally and Stratigraphically Distinct From the Holocene.” Science 351: 6269.

Zalasiewicz, J., C. N. Waters, C. P. Summerhayes, A. P. Wolfe, A. D. Barnosky, A. Cearreta, P. Crutzen, et al. 2017. "The Working Group on the Anthropocene: Summary of Evidence and Interim Recommendations.” Anthropocene 19: 55-60.

(C) 2019 Author(s)

This is an open-access article distributed under the terms of the Creative Commons Attribution 4.0 International license, which permits anyone to download, copy, distribute, display, or adapt the text without asking for permission, provided that the creator(s) are given full credit.

ISSN 2475-3025 